\title{
INSTRUCCIONES PARA AUTORES
}

La revista HAMUT'AY es una publicación semestral de la División de Investigación y Extensión Científica Tecnológica de la Dirección Universitaria de Educación a Distancia de la Universidad Alas Peruanas cuyo objetivo es divulgar artículos científicos a texto completo sobre tecnologías y virtualidad y se dirige a la comunidad universitaria nacional e internacional.

Todos los artículos son sometidos a arbitraje a través de pares evaluadores nacionales e internacionales de amplia trayectoria en la línea temática de la revista. Los pares no son miembros del Comité Editorial ni de la institución editora.

Los artículos que se remiten a la revista deben ser originales e inéditos, no se enviaron a otra revista para su publicación y no han sido publicados.

\section{TIPOS DE ARTÍCULOS A PUBLICAR}

La revista acepta tres categorías de artículos.

Artículos de investigación científica y tecnológica (López, 2013, Publindex, 2010). Son investigaciones originales que presentan resultados de uno o varios proyectos de investigación académico-tecnológica concluidos o en proceso.

Artículos de revisión (Fernández-Ríos y Buela-Casal 2009). Son síntesis de estudios bibliográficos de un tema determinado, en el que se analiza, sintetiza y discute la información publicada de una manera integrada.

Reportes de Casos (Publindex, 2010). Son presentaciones de resultados de un estudio de caso sobre una situación específica, que da a conocer las experiencias técnicas y metodológicas consideradas en el caso.

\section{ESTRUCTURA DE LOS TIPOS DE ARTÍCULOS}

Todos los artículos deberán ser redactados con el programa Word (Microsoft) usando las siguiente normas de estilo: Tamaño papel A4 con márgen izquierdo de $3 \mathrm{~cm}$. y $2.5 \mathrm{~cm}$. en los demás márgenes; fuente Times New Román, tamaño12 e interlineado a doble espacio.

En el encabezado deberá ir el título del artículo y los nombres completos de los autores, según el orden de participación. Cada una de las páginas del artículo debe estar numerada consecutivamente.

\section{Composición de los tipos de artículos}

Los artículos de investigación científica y tecnológica (López, 2013; Bobenrieth, 2002). Se componen del título, autor(es), resumen (abstract), palabras claves (keywords), introducción (objetivos), método (participantes, instrumento, diseño, procedimiento), resultados (interpretación tablas y figuras), discusión y conclusiones, referencias bibliográficas y agradecimientos y anexos (opcional). EFACYT.

Los artículos de revisión (Fernández-Ríos y Buela-Casal 2009, p.332). Están compuestos del título, autor(es), resumen (abstract), palabras claves (keywords), introducción, método (criterios de selección de la literatura) y revisión de la literatura (marco teórico del tema de revisión). EFAR

Tablas: El título será claro, conciso y descriptivo del contenido de la tabla. Solo la palabra inicial lleva mayúsculas y no se coloca punto al final del título. Veáse modelo siguiente:

\begin{tabular}{lcc}
$\begin{array}{l}\text { Herramientas de } \\
\text { virtualización }\end{array}$ & Tiempo (s) & CPU (\%) \\
\hline Xen & 109 & 35.14 \\
\hline Vmware & 105 & 85.49 \\
\hline VirtualBox & 87 & 82.88
\end{tabular}

Tabla 1. Tiempo transcurrido de arranque y consumo de CPU de las herramientas de virtualización

Figuras: Son gráficas, fotografías, diagramas y dibujos en formato JPG de calidad alta. El título será breve y conciso. Ejemplo en la página siguiente.

Referencias bibliográficas. Las referencias y citas bibliográficas deberán considerar las Normas APA, Sexta Edición. Veáse los siguientes ejemplos:

Artículos publicados en revistas: 


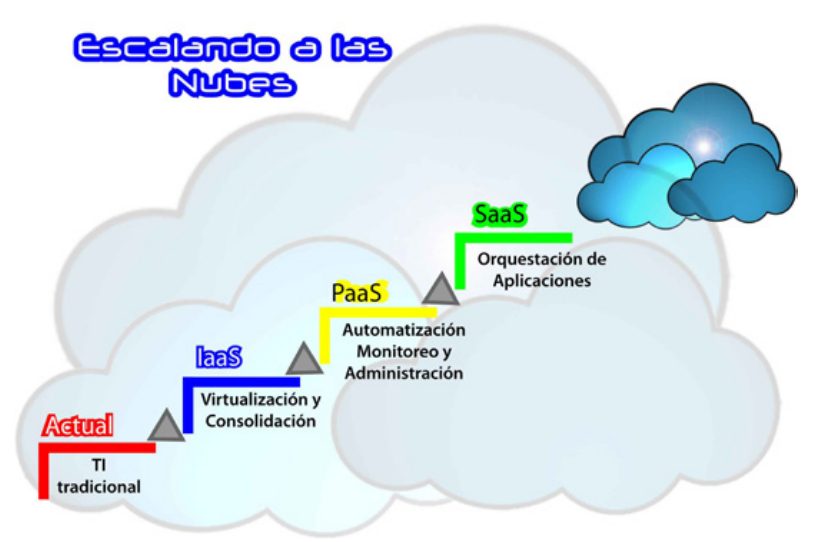

Figura 1. Escalando a las nubes. Fuente: http://www.eikonix.mx/?page_id=113

Cabero, J. (2010). Los retos de la integración de las TICs en los procesos educativos: Limites y pósibilidades, Rev Perspectiva Educacional, 49 (1), 36-61

\section{Libros:}

Cabello, R. \& Levis, D. (2007), Medios informáticos en la educación a principios del siglo XXI, (pp.107) 1era. Edición. Argentina: Publicaciones Prometeo Libros

\section{Capitulos de libros:}

García, A., Cocero, D., Velázquez, J., Blanco, E., Grande, M., Núñez, M.V. \& Tejera, R. Aplicación de la teledetección a la gestión silvopastoral (2006). En Camacho Olmedo, M., Cañete, J. \& Lara, J. El acceso a la información espacial y las tecnologías geográficas. (pp.831-842). España Granada: Editorial universidad de Granada

\section{Tesis:}

Carmona, J. (2012) Aplicaciones de la simulación tridimensional para la detección precoz de consumo de sustancias y violencia escolar en ámbitos educativos entre los ańos 2011 y 2012. Tesis doctoral, Universidad de Almería, Almería, España

\section{Páginas electrónicas:}

Fernandez-Rios \& Buela-Casal, G. (2009) Standars for the preparation and writing of psichology, Internacional Journal of Clinical and Health Psychology (internet) (citado el 15 de febrero del 2014), 9 (2), 329-344. Recuperado de http:// www.aepc.es/ijchp/ref-es-326.pdf

\section{ENVÍO DE ARTÍCULOS}

Los autores enviarán el artículo científico acom- pañado de la declaración jurada de autoría y autorización (DEJA) al Editor jefe de la revista (Dra. Cleofé Alvites Huamaní <revistahamutay@uap. edu.pe>. Los autores recibirán confirmación de la fecha de recepción de su trabajo.

\section{PROCESO DE EVALUACIÓN DE ARTÍCULOS}

La evaluación de los artículos tiene las siguientes fases:

Primera fase: El grupo editorial verifica el cumplimiento de los aspectos estructurales y de forma según las indicaciones para autores, en los formatos establecidos, y de acuerdo a al tipo de artículo.

Segunda fase: Los árbitros (pares revisores) determinan el valor del contenido del artículo y sus aspectos metodológicos, evaluando la calidad científica del artículo. Como resultado de esta fase, los pares evaluadores emiten uno de los siguientes criterios: No publica, Publica con condición (levantará observaciones previa a la publicación) y publica, considerando para ello los criterios estipulados en el PEAR o PEAO o PEEC, según sea el caso. Si se da el criterio de Publica con condición se remitirá al autor para que levante las observaciones, luego el autor volverá a remitirlo al par revisor para su arbitraje.

\section{REFERENCIAS BIBLIOGRÁFICAS}

Bobenrieth, M. (2002) Normas para revisión de artículos originales en Ciencias de la Salud. Revista Internacional de Psicología Clínica y de la Salud, 2 (4) 509-523

Fernandez-Ríos, L. y Buela-Casal, G. (2009) Standards for the preparation and writin of Psychology review articles. Revista International Journal of Clinical and Health Psychology, 9 (2) 329-344

López, S. (2013) El proceso de escritura y publicación de un artículo científico. Revista Electrónica Educare, 17 (1), 5-27. Recuperado de http://www.revistas.una.ac.cr/index. php/EDUCARE/issue/current

Romani, F. (2010) Reporte de caso y serie de casos: una aproximación para el pregrado. Revista CIMEL 15 (1), 46-51 recuperado de http://www.redalyc.org/articulo. oa?id=71720941013

Publindex (2010) Documento Guía, servicio permanente de indexación de Revistas de Ciencia, Tecnología e innovación Colombianas, Base Bibliográfica Nacional-BBN, Índice bibliográfico nacional Publindex-IBN 